\title{
Infectious Diarrhea, as a Valid Medical and Public, Worldwide Health Problematic
}

\author{
Deac Liana Monica \\ Public Health Institute, Babes - Bolyai University, Cluj, Romania.
}

Corresponding Author: Deac Liana Monica, Public Health Institute, Babes - Bolyai University, Cluj, Romania.

Received date: June 19, 2021; Accepted date: August 16, 2021; Published date: August 25, 2021

Citation: Deac L. Monica (2021) Infectious Diarrhea, as a Valid Medical and Public, Worldwide Health Problematic. J, Clinical Medical Reviews and Reports. 3(7); DOI:10.31579/2690-8794/093

Copyright: (C) 2021, Deac Liana Monica, This is an open access article distributed under the Creative Commons Attribution License, which permits unrestricted use, distribution, and reproduction in any medium, provided the original work is properly cited.

\begin{abstract}
Acute diarrhea of infectious etiology, referred to gastroenteritis and is associated with clinical signs and symptoms including: nausea, vomiting, abdominal pain and cramps, bloating, flatulence, fever, passage of bloody stools, tenesmus, and fecal urgency disorders [10]. Diarrheal illness is a problem worldwide, with substantial regional variation in the prevalence of specific pathogens [8]. In fact, Infectious diarrheal diseases, are the second leading cause of morbidity and mortality worldwide and can cause real public health problems. Such diarrhea was studied as a medical disorder, in a 3 year period, 2017-2020, in Transylvania region from Romania. It was found 3577 number of cases, almost during July to August. The case incidence for the disease arrived at $65 \%$, in the entire summer season. The data were transmitted by 12 district Sanitary Polices, to the Public Health Center. This all were mostly diagnosed by the territorial family doctors and more than $50 \%$, have need some days of hospitalization, because of several disease disorders. For this disorders it was used a specific adequate fluid and electrolyte replacement as key of the treatment, to managing diarrheal illnesses. Even so, 3 children under 5 year's age died, because of severe complications. Organic failed was estimate to be the cause of their deaths. Clinical and epidemiological evaluation defined the severity and type of this illnesses. The detected infectious etiology for the acute diarrhea, where determined in authorized Microbiology laboratories, and there were identified: Shigella spp, Salmonella spp, Campylobacter spp, Yersinia spp, Rotavirus, Giardia. Most number of cases appeared in children in $63 \%$, followed by elderly or adult people in $17 \%$ each, all data as quantified number of determined infectious diarrheas. Acute diarrheal illness had to be considered a major public health issue, against which control efforts are needed. Public health surveillance of infectious acute diarrhea, includes obligatory strategies of infection control. Good hygiene, hand washing, safe food preparation, and access to clean water are key factors in preventing diarrheal illness [11]

Key words: diarrhea symptoms, etiology, health survey
\end{abstract}

\section{Introduction}

Acute diarrhea is one of the most common diagnoses in general practice, and it remains responsible for high morbidity rates around the world [9]. On every year, according to the World Health Organization (WHO) and UNICEF data, there are about 2 billion cases of diarrheal disease worldwide. 1.9 million Children younger than 5 years of age, mostly in developing countries, perish from diarrhea each year. In industrialized countries, relatively few patients die from diarrhea, but even so, the disease continues to be an important cause of morbidity associated with substantial health care costs [7]. In general, it is recognized that acute diarrhea is a major cause of childhood mortality in developing countries; however, adult mortality from diarrhea is also not uncommon, particularly among the elderly, in whom the case-fatality ratio is even higher than in children [12]. However in the world, the morbidity from diarrheal diseases has remained relatively constant during the past 2 decades [4]. Regulatory medical authorities provide guidelines for the management of adult diarrhea, but how well physicians adhere to these guidelines has not been adequately assessed [6].

Because of all this epidemiological recognized world over details, the aim was to study even the diarrheal disease existing and reported as data in Romania. That for it was analyzed in the Epidemiology Department, from the Public Health Institute in Cluj, during 2017 - 2020, the morbidity caused by infectious diarrhea, appeared in Transylvania region. Despite the economic and societal burdens of diarrheal illnesses, there are still few clinical guidelines, which exist in correct use for the diagnosis and treatment of persons with such suspected or relevant infectious diarrheas in several lands as well even in Romania. That for, considerable clinical practice have been observed for to demonstrate a clear need of a clinical diagnostic, improved by specific guidelines. Public health interventions to promote hand washing alone can reduce the incidence of diarrhea by about one-third in the world. 


\section{Material and method}

The objective of this study was to identify the incidence, clinical characteristics, management and risk factors of identified diarrhea in our region. A cross-sectional study was conducted to evaluate identified acute diarrhea in Transylvania region. That for it was used practical an analytical descriptive epidemiological study, to analyze the 3577 cases of infectious diarrheas, identified in the population. It was so figured out all representative aspects of the pathology for: children, adults and elderly people. Data recruitment were ordered by the existing pathology in Ro by the National Public Health Guidelines. Obtained data were transmitted by the territory sanitary police units and were analyzed in the Public Health Institute, on each year, almost during 5 months, from May to November, in all the studied years from 2017-2020. All data offered an epidemiologic analyze and data interpretations of cases, during the entire mentioned time period.

\section{Results and Comments}

Figure 1. Present the 3577 infectious diarrheas appeared during 2017 to 2020 in Transylvania region from Romania.

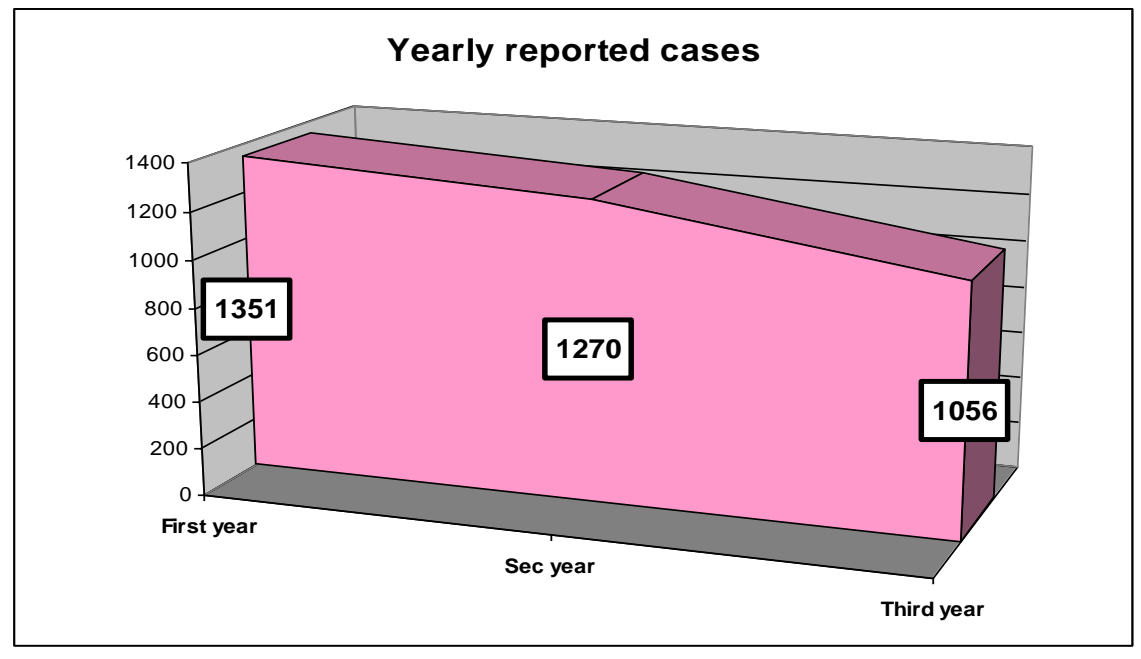

Figure. 1 Number of Infectious diarrheas

Most of the disease were present in the first year of the study, in 37\%. In the second year this were followed by $35.5 \%$ and at least in the third study year, in $29.5 \%$. In all this 3 years, the infectious pathology appeared in the summer season, almost during July and August. In the sum
Significant to be figured out is here, that infectious diarrhea, existed in the study, at each age decade. More significant it appeared to be in children, with $63 \%$, as Figure. 2 present data.

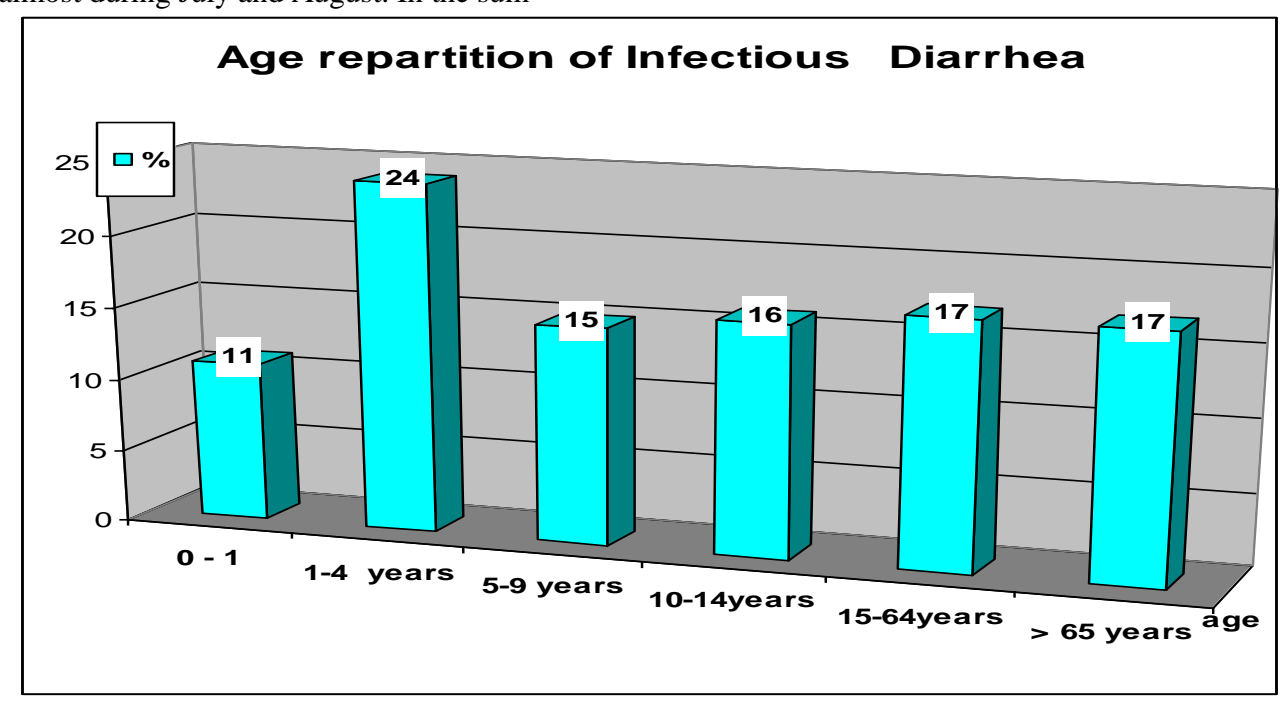

Figure 2. - Age of infectious diarrheas

Data made relevant that the disease was present at children, on 0-14 age. In adults infectious diarrhea was remarked in $17 \%$, as well in elderly people this pathology was represented in same order of cases - in $17 \%$. $27 \%$ of children and adults have need short hospitalization days, because of dehydration. For such disorders, it was used a specific adequate fluid and electrolyte replacement, as key of the treatment and managing diarrheal illnesses. 3 children under 5 year's age died, even after this specific therapy, because of other severe organic complications and organic fails caused their deaths.

International data, present a growing awareness of the potentially impact, of long-term disability, caused by repeated early childhood enteric infections. Worldwide, there are 3.1 million deaths due to diarrhea per year (18400 per day), mostly at young children in developing areas (1.12). 
Annual deaths due to diarrhea globally occur mainly in young children, and the number of deaths is 1000-fold higher than in the United States, where most of those who die of diarrheal illness, are elderly people [2].

Always, clinical and epidemiological evaluation must define the severity and type of this illnesses. A collaborative activity and work between clinicians and public health practitioners can make to get less severe evolution of the infectious diarrheas cases. That for clinicians, can early put the diagnosis of an acute episode of diarrhea and can lead to interventions that alleviate symptoms and prevent secondary possible other disease transmissions [4, 11]. For public health practitioners, prompt notification of pathogen-specific diagnoses and bacterial isolates through public health surveillance, can low the rates of transmission and lead to timely detection and control of any disease outbreaks. Because both clinicians and public health practitioners share overlapping responsibilities for such diagnosis, management, and prevention of infectious diarrheal diseases, must contain specific recommendations and specific guidelines for both groups of specialists [5, 9].

Diarrheal illness is a problem worldwide, with substantial regional variation in the prevalence of specific pathogens [7, 10]. Testing of stool specimens is always indicated for each patient with enteric disorders. This had to be ordinate up to an existing national guideline, for to can identify all microbiological specimens. That for, it was figured out, the etiological aspects concerning all detected cases of infectious diarrheas. Data were received from several territory laboratories, where it was realized pertinent microbiological investigations. All this data were identified, in order to present the microorganisms and their aspects. With, it was possible to make an overview, concerning the heterogenic microorganisms, who made the appearance of the infectious diarrhea diseases, present in the Transylvania population study. The incidence of this aspects, is presented in Figure 3, in which it is shown out all identified germs.

\section{Incidence of microbiological etiology}
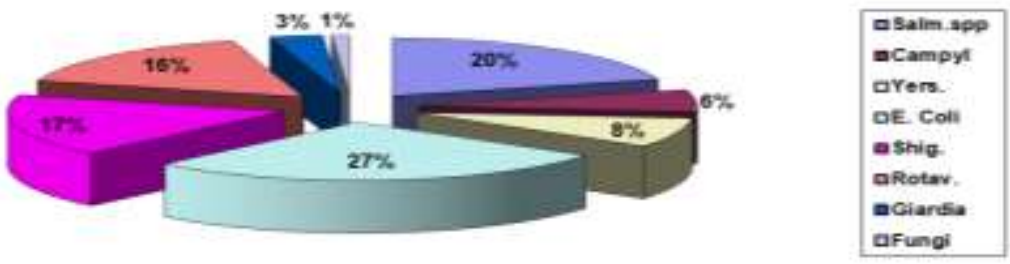

Figure 3. Detected microbiological aspects

Most of germs species belonged to the Enterobacteriaceae Family, represented by E coli in $27 \%$, Salmonella spp. in 20\%; Shigella spp., in $17 \%$. Important is to be figured out is, that the death of the 3 children under 5 age were caused by invasive $E$. coli, present in their stool samples. It is also important to be remarked the presence of Yersinia spp. in $8 \%$ and of Campylobacter spp.. In $6 \%$, in other patients samples. The presence of the many different bacterial species were different identified: $E$. Coli in children faces and all other germs were present in adults, or in the elderly people samples. The observation mention the presence, in 17 $\%$ of Rotavirus, which mostly were present in the infectious diarrhea of the children. $3 \%$ of children have had even Giardia in their samples and $1 \%$ of elderly people have had Fungi in their preserved tools. Many of these organisms can easily be transmitted through infected food or water, or from person to person, as the epidemiological study figured out in the Transylvania territory infectious diarrhea cases.

There are various interpretations of what is considered medically indicated for evaluating persons with infectious diarrhea today. Stool cultures are often viewed as important tests, with a high result significances [3]. With the rapid globalization and industrialization of our food supply, more recognized pathogens can appear or can be figured out worldwide. More with a multiplicity of recognized pathogens, new Laboratory diagnostic of tool samples can be done and so can even change the known before aspects. The challenges of determining optimal, costeffective means for such appropriate diagnosis, clinical management, and public health control of diarrheal illnesses knowledge [6]. This will continue to evolve as improved understanding of pathogenesis and development and can bring in use more rapid tests, who will improve the diagnosis and management of infectious diarrheal illness. It had to be accepted that this diseases are one of the most common clinical syndromes in our society. That's why the lack of a specific diagnosis today, can hinder appropriate management and treatment of many such infections. Observation of patients is a recommendation, for to provide always to clinicians and public health practitioners, consensus-based correct document [9]. These will aid in the management of acute diarrheas, by addressing data, which patients to be tested, what tests to order, what medical treatments to be used, and what steps to take to ensure, that appropriate public health actions, are always implemented, well enough [11].

\section{Conclusions}

The 3 years study demonstrate that infectious diarrhea appear during the summer months, almost from July to August.

Significant incidence was at Children, of 0-14 age group, but each patient should be observed about potential epidemiological risk factors, for any diarrheal diseases, or for possible spread infection in the territory.

For evaluating of all persons with any enteric infections, all bacterial, viral, and parasitic pathogens had to be identified.

To reduce the morbidity and possible mortality in infectious diarrheas, it is need a serious clinical and public health study, that require specific control measures in clinics and health care activity group, to identify optimal diagnostic, treatment, and prevention methods.

\section{References}

1. Adkins HJ, Escamilla J, Santiago LT, et al. (1987) Two-year survey of etiologic agents of diarrheal disease at San Lazaro Hospital, Manila Republic of the Philippines. J Clin Microbiol. 25: 1143-1147. 
2. DuPont HL: (2014) Acute infectious diarrhea in immunocompetent adults. $N$ Engl J Med. 370 (16): 1532-1540.

3. Farthing M, Salam MA, Lindberg G, Dite P, Khalif I, et al (2013), Review team: Acute diarrhea in adults and children: a global perspective. J Clin Gastroenterol. 47: 12-20.

4. Matthew R. Riley R, Dorsey Bass, in Pediatric Gastroenterology, 2008.

5. Guerrant RL, Van Gilder T, Steiner TS, et al. (2001) Infectious Diseases Society of America. Practice guidelines for the management of infectious diarrhea. Clin Infect Dis. 32(3):331351.

6. Matthew R. Riley R, Dorsey Bass, in Pediatric Gastroenterology, 2008

7. Slotwiner-Nie PK, Brandt LJ: (2001) Infectious diarrhea in the elderly. Gastroenterol Clin North Am. 30 (3): 625-635. 10.1016/S0889-8553(05)70202-8.
8. Snyder JD, Merson MH. (1982) The magnitude of the global problem of acute diarrheal disease: a review of active surveillance, data. Bull, WHO. 60:605-613.

9. Van Cauteren D, De Valk H, Vaux S, Le Strat Y, Vaillant V: (2012) Burden of acute gastroenteritis and healthcare-seeking behaviour in France: a population-based study. Epidemiol Infect. 140 (4): 697-705.

10. Walker CL, Black RE: (2010) Diarrhoea morbidity and mortality in older children, adolescents, and adults. Epidemiol Infect. 138 1215-1226. 10.1017

11. WHO Program for the Control of Diarrheal Diseases. CD update on persistent diarrhea. No.4, March 1989.

12. WHO. The management and prevention of acute diarrhea: practical guidelines. 3d ed. Geneva: World Health Organization.
This work is licensed under Creative Commons Attribution 4.0 License

To Submit Your Article Click Here: Submit Manuscript

DOI: $10.31579 / 2690-8794 / 093$
Ready to submit your research? Choose Auctores and benefit from:

* fast, convenient online submission

* rigorous peer review by experienced research in your field

* rapid publication on acceptance

* authors retain copyrights

* unique DOI for all articles

* immediate, unrestricted online access

At Auctores, research is always in progress.

Learn more auctoresonline.org/journals/clinical-medical-reviews-andreports 